\title{
COMPOSIÇÃO E ESTRUTURA DA COMUNIDADE ARBÓREA E ARBUSTIVA EM MURUNDUS NO PANTANAL DE POCONÉ, MATO GROSSO ${ }^{1}$
}

\author{
Rodrigo Ferreira Morais², Fernando Ferreira Morais ${ }^{3}$ e Jose Francisco de Lima ${ }^{4}$
}

\begin{abstract}
RESUMO - Campos de murundus são áreas planas alagáveis, onde se encontram pequenas elevações (morrotes) espalhadas na paisagem. Esses murundus apresentam solo e vegetação diferente da área circundante, uma vez que não se alagam no período chuvoso. Espera-se que o tamanho $\left(\mathrm{m}^{2}\right)$ e o volume $\left(\mathrm{m}^{3}\right)$ dos murundus exerçam influência sobre a composição florística e a estrutura da comunidade vegetal. Assim, o objetivo deste trabalho foi analisar a composição florística e a estrutura da comunidade vegetal arbórea e arbustiva em murundus, no Pantanal de Poconé, MT, com a finalidade de responder a duas perguntas: (i) Existe correlação entre a área e o volume do murundu com a riqueza e abundância da vegetação arbórea e arbustiva? (ii) Existe correlação entre a área e o volume do murundu com a área basal das espécies arbóreas e arbustivas? Foram usadas parcelas para delimitar a área de campo de murundus a ser estudada. Nessas parcelas, formam mensurados a área e volume dos murundus e realizados os levantamentos florístico e fitossociológico. Foi verificado que área e volume influenciaram a riqueza, a abundância e a área basal das espécies.
\end{abstract}

Palavras-chave: Biogeografia; Fitossociologia; Campo de inundação.

\section{COMPOSITION AND STRUCTURE OF TREE AND SHRUB COMMUNITY IN THE EARTHMOUND IN PANTANAL AT POCONÉ, MATO GROSSO}

\begin{abstract}
Earthmounds fields are flat floodplain, which contain small elevations (morrotes) scattered in the landscape. These earthmounds have different soil and vegetation from the surrounding area, since it does not overflow during the rainy season. It is expected that the size $\left(\mathrm{m}^{2}\right)$ and volume $\left(\mathrm{m}^{3}\right)$ of the earthmounds exert influence on the floristic composition and plant community structure. Thus, the aim of this study was analyze the floristic composition and community structure of trees and shrubs in earthmounds in the Pantanal of Poconé, MT, in order to answer two questions: (i) Is there a correlation between the area and volume of the earthmounds with richness and abundance of tree and shrub vegetation? (ii) Is there a correlation between the area and volume of the earthmounds with the basal area of trees and shrubs? Were plots used to delimit the area of earthmounds field to be studied. In each plot, we measured the area and volume of each earthmounds and conducted the floristic and phytosociological survey. We observed that the area and volume influenced the richness, abundance and basal area of the species.
\end{abstract}

Keywords: Biogeography; Phytosociology; Flood field.

\footnotetext{
${ }^{1}$ Recebido em 29.05.2013 aceito para publicação em 13.03.2014.

${ }^{2}$ Programa de Pós-Graduação em Ciencias Biologicas (Biologia Vegetal), Universidade Estadual Paulista Júlio de Mesquita Filho, UNESP, Brasil.E-mail: <morais_rf@yahoo.com.br>.

${ }^{3}$ Departamento de Ciências Biológicas, Campus Cáceres, Universidade do Estado de Mato Grosso, MT, Brasil. E-mail: $<$ moraisrf@hotmail.com>.

${ }^{4}$ Centro Universitário, Univag, Várzea Grande, MT, Brasil. E-mail: <romoraisbio@homail.com>.
} 


\section{INTRODUÇÃO}

O Pantanal é uma depressão sazonalmente alagável e compreende aproximadamente $140.000 \mathrm{~km}^{2}$ (BRASIL, 1982). Situa-se quase que inteiramente em território brasileiro, pertencente à Bacia do Alto Paraguai, integrante da Bacia Hidrográfica Platina, e encontra-se na porção central da América do Sul (JUNK; CUNHA 2004). Está inserido na Região Centro-Oeste, de forma que 35\% de sua área situa-se no Estado de Mato Grosso e 65\% no Estado de Mato Grosso do Sul (ABDON; SILVA, 2008).

Esse bioma é a maior área úmida tropical e a principal área alagável do Brasil (SANTOS et al., 2009), cuja vegetação se distribui por quatro regiões fitoecológicas: Savana (Cerrado), Savana Estépica (Chaco), Floresta Estacional Decidual e Floresta Estacional Semidecidual (ABDON; SILVA, 2008).

Para Silva et al. (2000), no Pantanal foram identificadas 16 classes de vegetação com base nas fitofisionomias, sendo os campos a fisionomia mais representativa (31\%), seguidos do Cerradão (22\%), Cerrado (14\%), campos inundáveis (7\%), floresta semidecídua (4\%), mata de galeria $(2,4 \%)$ e tapetes de vegetação flutuantes ou "baceiros” $(2,4 \%)$.

Em diversas dessas regiões pantaneiras, principalmente nas fitofisionomias Savânicas alagáveis, pequenas elevações de terra de forma elíptica com diâmetro de 0,5 a 20 m e alturas de 0,2 a 2 m, denominadas murundus, espalham-se pela paisagem, conferindo-lhe um aspecto encalombado (FURLEY, 1986; FURLEY, 1990; OLIVEIRA-FILHO, 1992).

Campos de murundus como os do Pantanal são encontrados em áreas afetadas por chuvas sazonais e pelo transbordamento de leitos de rios e possuem contatos periódicos durante o período de cheia com os corpos hídricos (FURLEY, 1986). Para esse mesmo autor, murundus variam em tamanho, formato, tipo, diversidade de cobertura vegetal, propriedades do solo e profundidade do lençol freático. Essa fitofisionomia é caracterizada por uma área plana, inundável no período das chuvas, quando se encontram distribuídos os murundus. A área plana é coberta por vegetação campestre, e os murundus são ocupados por vegetação lenhosa do Cerrado, ou xérica, nos pontos mais altos dos murundus (ARAÚJO NETO et al., 1986; FURLEY, 1990; OLIVEIRA-FILHO, 1992; PONCE; CUNHA, 1993; RESENDE et al., 2004; MARIMON et al., 2009).
Referente às hipóteses sobre a origem dos murundus, Oliveira-Filho (1992) e Ponce e Cunha (1993) defendem que atividades térmitas foram os responsáveis pela elevação da microtopografia acima da vegetação campestre. Mas Silva et al. (2010), apoiados por hipóteses anteriores (ARAÚJO NETO et al., 1986; FURLEY, 1986), comprovaram, através de análises de isótopos de carbono retirados do solo, que processos erosivos diferenciais produziram o formato típico dos murundus.

São poucos os estudos realizados em campos de murundus nos últimos anos (por exemplo, ARAUJO NETO et al., 1986; OLIVEIRA-FILHO, 1992; RESENDE et al., 2004; SILVA et al., 2010), e sobre o Pantanal de Poconé são ainda escassos os trabalhos que relacionem características abióticas com a composição florística e estrutura da comunidade vegetal nessa fitofisionomia.

Em uma abordagem ecológica, os murundus são responsáveis por parte dos recursos alimentares e constituem áreas de refúgio permanentes ou temporários para várias espécies (MARIMON et al., 2009), atuando como ilhas de vegetação (OLIVEIRA-FILHO, 1992), que protegem indivíduos jovens da submersão no período de cheia (SOARES; OLIVEIRA, 2009).

Em um contexto de distribuição da diversidade biológica, a teoria da biogeografia de ilhas (MACARTHUR; WILSON, 1967) propõe explicar a diferença de diversidades de espécies de acordo com o tamanho e a distância entre as ilhas; assim, murundus maiores poderiam ter composição florística e estrutura diferentes dos murundus menores.

Espera-se, assim, que o tamanho e volume do murundu exerçam influência sobre a composição florística e estrutura da comunidade vegetal. Para tanto, este trabalho visou responder a duas perguntas: (i) Existe correlação entre a área e o volume do murundu com a riqueza, abundância da vegetação arbórea e arbustiva?; e (ii) Existe correlação entre a área e o volume do murundu com a área basal das espécies arbórea e arbustiva?

\section{MATERIAL E MÉTODOS}

\subsection{Descrição da área}

Este trabalho foi realizado na região Norte do Pantanal, no Município de Poconé, Estado de Mato Grosso, na coordenada $16^{\circ} 19$ ' $10^{\prime \prime}$ S 56 31'48'’O e altitude de $124 \mathrm{~m}$. O Pantanal Mato-Grossense é uma 
depressão sazonalmente alagável, totalmente contida na bacia de drenagem do Alto Paraguai e compreende aproximadamente $140.000 \mathrm{~km}^{2}$ (RADAMBRASIL, 1982). No Estado de Mato Grosso, situa-se no extremo Oeste do território brasileiro, compreendendo os Municípios de Poconé, Santo Antonio do Leverger, Cáceres, Barão de Melgaço e Nossa Senhora do Livramento. Enquadra-se entre os paralelos de $16^{\circ}$ a $22^{\circ}$ de latitude Sul e os meridianos de $55^{\circ}$ a $58^{\circ}$ de longitude Oeste.

O clima da região é do tipo AW, de acordo com a classificação de Köppen com duas estações bem definidas: a estação seca de maio até setembro e a estação chuvosa de outubro a abril (CUNHA; JUNK 1999). A precipitação máxima chega a 1.384 mm no mês de janeiro e a mínima no mês de julho. A temperatura média anual é de $25,8^{\circ} \mathrm{C}$, sendo outubro o mês mais quente e julho, o mais frio. O processo de inundação sazonal é dividido em quatro fases: enchente e cheia (outubro a abril), vazante e seca (maio a setembro) (REBELLATO; CUNHA, 2005).

\subsection{Coleta e análise dos dados}

Para o levantamento florístico e a obtenção dos parâmetros da estrutura da comunidade vegetal, foram instaladas quatro parcelas de $50 \mathrm{~m}$ x $50 \mathrm{~m}$, equidistantes $50 \mathrm{~m}$. Dentro de cada parcela, todos os murundus foram numerados com placas de alumínio e mensurados o comprimento (maior extensão) e a largura (menor extensão) para cálculo da área e, além dessas medidas, também foi medida a altura dos murundus para cálculo de volume.

Para medir a altura de cada murundu, foram utilizadas duas réguas graduadas. Uma régua foi posicionada na região central do murundu (parte mais elevada) e a outra, na porção plana do terreno. Com o uso de uma mangueira transparente flexível de $10 \mathrm{~m}$ de comprimento, lúmen de $3 / 8$ de polegadas e parede de $1 \mathrm{~mm}$ de espessura, foi mensurado o desnível entre os dois pontos, atribuídos a essa diferença à altura do murundu.

Para cada murundu foi calculada a área $\left(\mathrm{m}^{2}\right)$ e o volume $\left(\mathrm{m}^{3}\right)$, conforme descrito por Oliveira-Filho (1992), utilizando-se as seguintes equações: área $=(\boxplus / 4)$ $x$ (comprimento $x$ largura) e volume $=(\bigoplus / 6) x$ (comprimento x largura $x$ altura).

Para o levantamento florístico foram coletados todos os indivíduos em fase reprodutiva e as amostras herborizadas conforme orientações de Fidalgo e Bononi
(1984). As amostras foram identificadas no herbário da Universidade Federal de Mato Grosso (UFMT), por meio de comparação com exsicatas, consulta a especialista e à bibliografia especializada. A nomenclatura utilizada foi a proposta pela APG III (SOUZA; LORENZI, 2012). O material encontra-se depositado no Herbário do Centro Universitário UNIVAG, Várzea Grande, MT.

Para levantamento dos parâmetros fitossociológicos, todos os indivíduos estabelecidos nos murundus com perímetro à altura do solo (PAS) $\geq 15 \mathrm{~cm}$ foram amostrados e devidamente numerados, mensurados e identificados.

As parcelas foram utilizadas para delimitar as áreas de estudo e os murundus, considerados as unidades amostrais. Os parâmetros fitossociológicos relativos utilizados foram os descritos por Mueller-Dombois e Ellenberg (1974): densidade, frequência e dominância. Para cálculo de dominância e densidade relativas, utilizouse a soma das áreas dos murundus. Para esse fim, foi utilizado o pacote de programas do FITOPAC 2 (SHEPHERD, 2010).

Para verificar a relação do volume e área do murundu com a abundância, riqueza e área basal e a relação da abundância com riqueza e área basal, foi realizada a análise de regressão com ajuste de curva para verificar o melhor modelo de regressão que se ajustasse à relação estudada. Para as análises de regressão foi utilizado o programa Biostat 5.0.

\section{RESULTADOS}

Nos 64 murundus amostrados, foram coletadas 35 espécies, 32 gêneros e 27 famílias botânicas, conforme Tabela 1. As famílias com maior número de espécies foram Fabaceae com cinco espécies e Dilleniaceae, Euphorbiaceae e Ochnaceae, todas com duas espécies. As demais famílias apresentaram somente uma espécie cada. As espécies que apresentaram maior número de indivíduos amostrados foram Bromelia balancae Mez., Curatela americana L., Alchornea discolor Poepp., Miconia albicans (Sw.) Triana, Alibertia edulis (Rich.) A. Rich. e Vochysia divergens Volg.

A Tabela 2 apresenta os valores fitossociológicos da vegetação arbórea e arbustiva. As espécies que apresentaram maiores valores de FR, DR e DoR foram: Curatela americana, Alchornea discolor, Alibertia

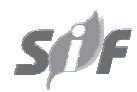

Revista Árvore, Viçosa-MG, v.38, n.3, p.443-451, 2014 
Tabela 1 - Lista florística de murundus no Pantanal de Poconé, MT, Fazenda São Sebastião (N = número de indivíduos e $\mathrm{FA}$ = frequência absoluta).

Table 1 - Floristic list of earthmounds at Pantanal of Poconé, MT, Fazenda São Sebastião ( $N$ = number of individuals and $F A=$ absolute frequency).

\begin{tabular}{|c|c|c|c|}
\hline Família & Espécie & $\mathbf{N}$ & FA \\
\hline Annonaceae & Annona dioica A.St.-Hil. & 66 & 15 \\
\hline Arecaceae & Allagoptera campestris (Mart.) Kuntze & 1 & 1 \\
\hline Asteraceae & Vernonia ferruginea Less. & 1 & 1 \\
\hline Bignoniaceae & Tabebuia aurea (Silva Manso) Benth. \& Hook.f. ex S.Moore & 5 & 3 \\
\hline Bromeliaceae & Bromelia balansae Mez. & 357 & 14 \\
\hline Convolvulaceae & Ipomoea rubens Choisy & 1 & 1 \\
\hline Costaceae & Costus arabicus L. & 1 & 1 \\
\hline \multirow[t]{2}{*}{ Dilleniaceae } & Curatela americana $\mathrm{L}$. & 213 & 44 \\
\hline & Davilla elliptica A.St-Hil. & 56 & 12 \\
\hline Erythroxylaceae & Erytroxylum suberosum A.St.-Hil. & 2 & 2 \\
\hline \multirow[t]{2}{*}{ Euphorbiaceae } & Alchornea discolor Poepp. & 656 & 37 \\
\hline & Mabea paniculata Spruce ex Benth. & 1 & 1 \\
\hline \multirow[t]{5}{*}{ Fabaceae } & Andira cuiabenses Benth. & 4 & 3 \\
\hline & Bauhinia glabra Jacq. & 12 & 6 \\
\hline & Bowdichia virgilioides Kunth. & 1 & 1 \\
\hline & Dipteryx alata Vogel. & 4 & 3 \\
\hline & Hymenaea stigonocarpa Mart. & 4 & 3 \\
\hline Lithraceae & Lafoensia pacari A.St.-Hil. & 1 & 1 \\
\hline Malpighiaceae & Byrsonima orbignyana A. Juss. & 16 & 11 \\
\hline Melastomatacee & Miconia albicans (Sw.) Triana & 185 & 29 \\
\hline Moraceae & Pseudolmedia sp. & 7 & 3 \\
\hline Myrtaceae & Eugenia inundata DC. & 2 & 1 \\
\hline \multirow[t]{2}{*}{ Ochnaceae } & Agonandra brasiliensis Miers ex Benth. \& Hook.f. & 1 & 1 \\
\hline & Ouratea castaneifolia (DC.) Engl. & 1 & 1 \\
\hline Rubiaceae & Alibertia edulis (Rich.) A.Rich. & 268 & 36 \\
\hline Salicaceae & Casearia sylvestris Swart. & 3 & 1 \\
\hline Simaroubaceae & Simarouba amara Aubl. & 4 & 3 \\
\hline Smilacaceae & Smilax fluminesis Steud. & 1 & 1 \\
\hline Urticaceae & Cecropia pachystachya Trécul. & 7 & 5 \\
\hline Vitaceae & Cissus erosa Rich. & 21 & 7 \\
\hline Vochysiaceae & Vochysia divergens Volg & 188 & 29 \\
\hline
\end{tabular}

edulis e Vochysia divergens que, juntas, apresentaram 72,5\% da frequência relativa, 91,37\% da densidade relativa e $87,16 \%$ dos valores de dominância relativa.

A relação da riqueza de espécies foi significativa e positiva para com a área que apresentou $\mathrm{R}^{2}=0,84$ e volume dos murundus com valor de $\mathrm{R}^{2}=0,86$, conforme apresentado na Figura 1AB.

A influência da área dos murundus na abundância apresentou relação linear positiva com $\mathrm{R}^{2}=0,83$, o mesmo observado no volume do murundu, que apresentou $\mathrm{R}^{2}=0,78$ (Figura 2AB).

A influência da área $\left(\mathrm{m}^{2}\right)$ dos murundus na área basal das espécies apresentou relação linear positiva com $\mathrm{R}^{2}=0,68$, tendo sido o mesmo padrão para o volume $\left(\mathrm{m}^{3}\right)$ do murundu, pois apresentou $\mathrm{R}^{2}=0,78$ (Figura $3 \mathrm{AB}$ ).

\section{DISCUSSÃO}

O resultado do levantamento florístico corrobora os resultados apresentados por Araújo Neto et al. (1986), Furley (1986), Oliveira-Filho (1988, 1992) e Resende et al. (2004), que indicaram que os murundus são ocupados por espécies típicas de Cerrado, principalmente nas regiões mais altas dos murundus. Para Marimon et al. (2009), entre outras espécies típicas de murundus, destacam-se: D. alata, A. cuyabensis, T. aurea, C. americana, E. suberosum, Bauhinia rufa e B. orbignyana e os gêneros Vochysia e Bauhinia.

As espécies mais abundantes e frequentes nesta pesquisa vêm de acordo com Oliveira-Filho (1988). A espécie C. americana apresentou maior frequência e está entre as mais abundantes em razão, possivelmente,

Revista Árvore, Viçosa-MG, v.38, n.3, p.443-451, 2014 
Tabela 2 - Parâmetros fitossociológicos da vegetação de murundus no Pantanal de Poconé, MT (FR = frequência relativa, $\mathrm{DR}=$ densidade relativa e DoR = dominância relativa).

Table 2 - Phytosociological parameters of the earthmounds vegetation at Pantanal of Poconé, MT (FR = relative frequency, $D R=$ relative density and $D o R=$ relative dominance $)$.

\begin{tabular}{lccc}
\hline Espécie & FR\% & DR\% & DoR\% \\
\hline Curatela americana L. & 22,00 & 14,70 & 50,50 \\
Alchornea discolor Poohl & 18,00 & 45,20 & 22,58 \\
Alibertia edulis A.St-Hil. & 18,00 & 18,50 & 4,73 \\
Vochysia divergens Volg.Ti. & 14,50 & 12,97 & 9,35 \\
Annona dioica A.St.-Hil. & 7,50 & 4,55 & 0,12 \\
Byrsonima orbignyana A.Juss. & 5,50 & 1,10 & 2,52 \\
Dipteryx alata Vogel. & 1,50 & 0,28 & 2,77 \\
Cecropia pachystachya Tréc. & 2,50 & 0,48 & 0,59 \\
Tabebuia aurea (Manso) Benth. & 1,50 & 0,35 & 1,26 \\
Pseudolmedia sp. & 1,50 & 0,48 & 0,90 \\
Hymenaea stigonocarpa Mart. & 1,50 & 0,28 & 1,10 \\
Andira cuyabensis Benth. & 1,50 & 0,28 & 0,03 \\
Simarouba amara Aubl. & 1,50 & 0,28 & 0,91 \\
Casearia sylvestris Swart. & 0,50 & 0,21 & 0,36 \\
Lafoensia pacari A.St.-Hil. & 0,50 & 0,07 & 0,29 \\
Bowdichia virgilioides Kunth. & 0,50 & 0,07 & 0,27 \\
Agonandra brasiliensis Miers. & 0,50 & 0,07 & 0,26 \\
Eugenia inundata DC. & 0,50 & 0,07 & 0,09 \\
Erithroxylum suberosum A.St.-Hil. & 0,50 & 0,07 & \\
\hline
\end{tabular}
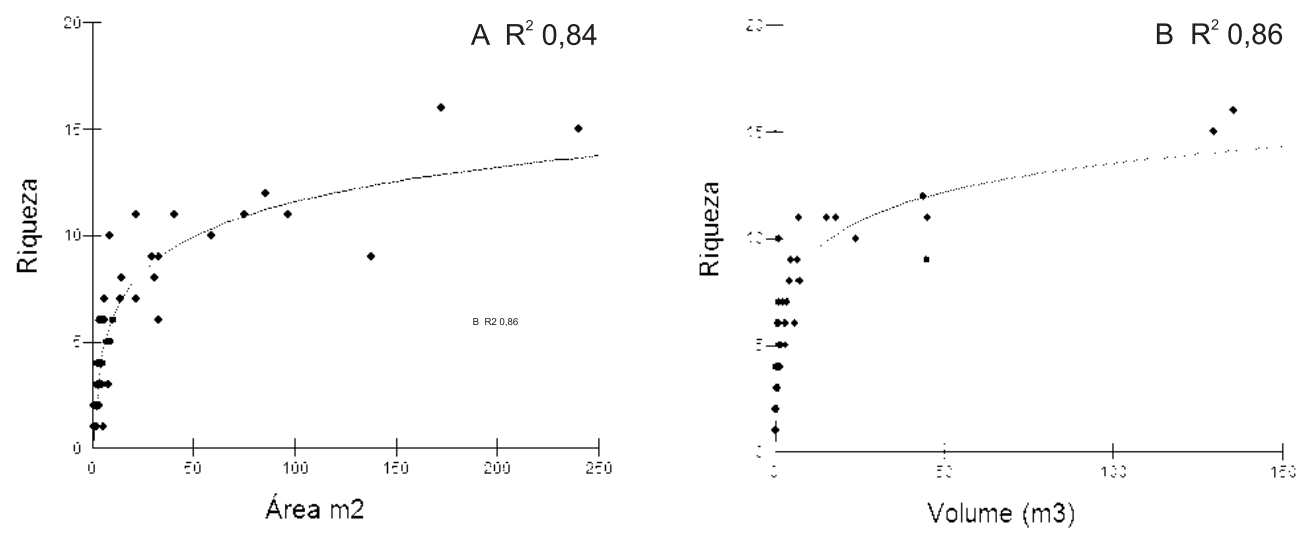

Figura 1 - Relação entre riqueza de espécies e área dos murundus (A) e relação entre riqueza de espécies e volume dos murundus (B) no Pantanal de Poconé, MT.

Figure 1 - Relation between species richness and earthmounds area (A) and relation between species richness and earthmounds volume (B) at Pantanal, Poconé, MT.

da alta sobrevivência das plântulas devido à ausência de inundação do murundu na área de estudo. Resultado similar foi encontrado por Bordignon et al. (2007), Oliveira-Filho (1988) e Marimon et al. (2009). Resende et al. (2004) abordaram que essa espécie é a mais importante em murundus do Pantanal e uma das mais tolerantes à variação sazonal e estresse hídrico do solo.
Outras espécies que se destacaram em abundâncias e frequência foram $A$. discolor e $V$. divergens. Segundo Arieira e Cunha (2006), para V. divergens há baixa tolerância ao estresse da seca e apresenta grande produção de sementes, o que pode justificar a alta abundância e frequência. Para Macedo et al. (2000), A. discolor possui período de frutificação cheia na seca, o que pode propiciar alto número de indivíduos. 

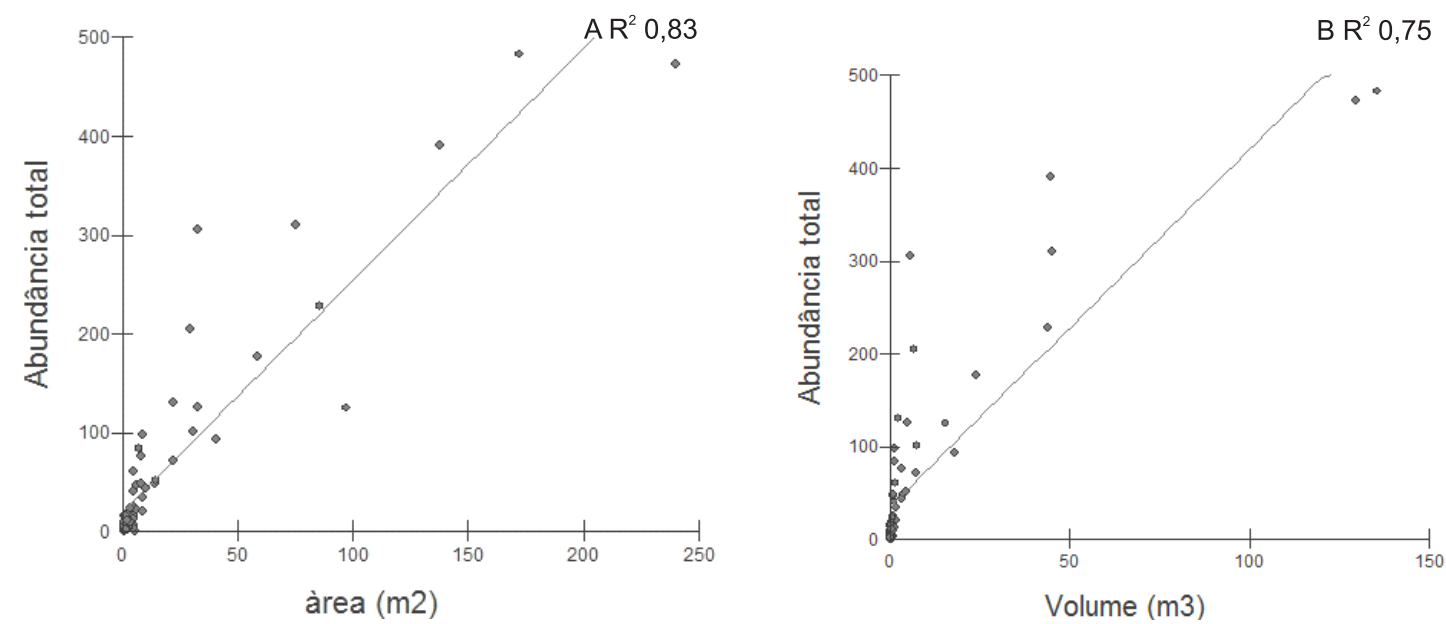

Figura 2 - Relação entre abundância total e área dos murundus (A) e relação do volume e abundância total dos murundus (B) no Pantanal de Poconé, MT.

Figure 2 - Relation between total abundance and earthmounds area (A) and relation between volume and total abundance of the earthmounds (B) at Pantanal, Poconé, MT.
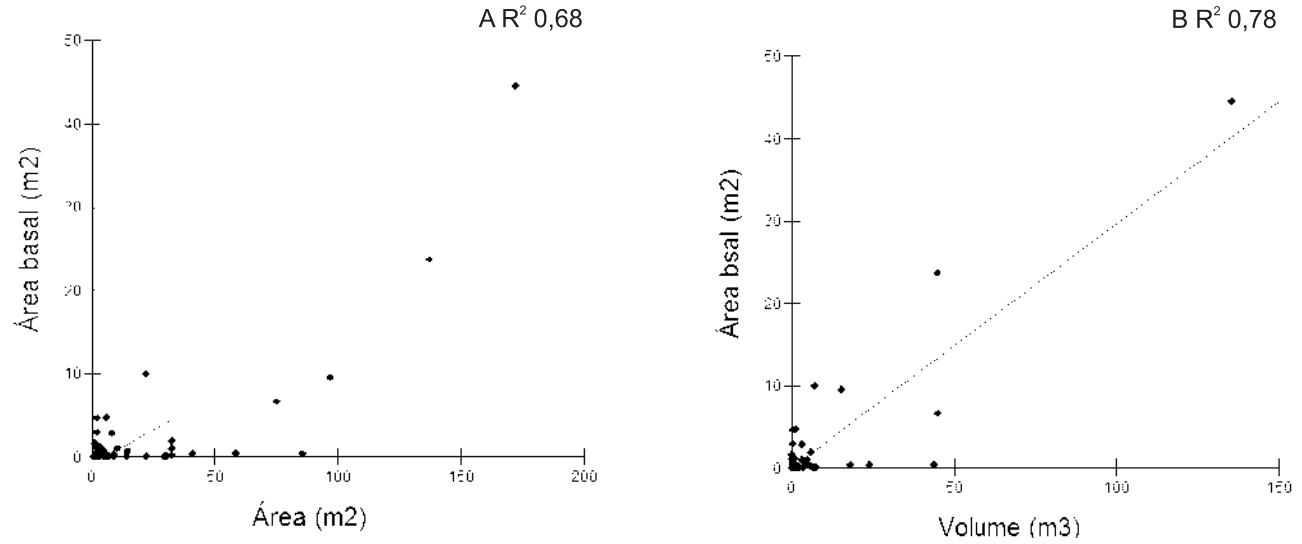

Figura 3 - Relação entre área basal das espécies e área dos murundus (A) e relação entre área basal das espécies e volume dos murundus (B) no Pantanal de Poconé, MT.

Figure 3 - Relation between species' basal area and earthmounds area (A) and relation between species' basal area and earthmounds volume (B) at Pantanal, Poconé, MT.

Os altos valores de abundância e frequência para B. balancae nos murundus corroboram os resultados de Oliveira-Filho (1988) e Almeida et al. (2009). Para estes últimos autores, as espécies da família Bromeliaceae possuem papel ecológico na melhoria das condições de sítios para o estabelecimento de outras espécies e disponibilizam recursos que são atrativos para a fauna.

O resultado da fitossociologia corroboram aqueles apresentados por Oliveira-Filho (1988), que encontrou os maiores valores para C. americana, A. edulis, D. alata,
A. cuyabensis e T. aurea. Bordignon et al. (2007) indicaram as espécies mais representativas em termos de valores fitossociológicos C. americana, S. versicolor, B. orbignyana e D. alata. Os resultados desta pesquisa vêm de acordo com Soares e Olivieta (2009), que indicaram T. aurea como a principal espécie que cresce sobre os murundus, no entanto nem sempre como espécie dominante.

Os murundus com maiores áreas e volumes apresentaram maior riqueza, e houve tendência de estabilização da riqueza conforme o aumento da área

Revista Árvore, Viçosa-MG, v.38, n.3, p.443-451, 2014 
e do volume. Isso pode estar relacionado à distância dos campos de murundu de áreas vizinhas e saturação hídrica do solo no entorno dos murundus, o que pode limitar a dispersão de algumas espécies. De acordo com Soares e Oliveira (2009), o crescimento sobre os murundus provavelmente seja fator que permite a sobrevivência das plântulas em períodos de inundação, quando estes protegem os indivíduos jovens da submersão, uma vez que na área de estudo não ocorre inundação dos murundus.

Para Bordignon et al. (2007), murundus com áreas maiores apresentam maior riqueza, e a distância dos murundus de fragmentos vizinhos influencia a colonização dos murundus. Segundo Marimon e Lima. (2001) e Resende et al. (2004), a saturação hídrica do solo é um caráter seletivo e pode acarretar diferenças florísticas, pois algumas espécies não são capazes de tolerar solos hidromórficos. Oliveira Filho (1992) e Furley (1986) abordaram que o volume do murundu está relacionado com o potencial de drenagem e pode influenciar a respiração das raízes e a possibilidade de estabelecimento de plantas com raízes profundas devido ao lençol freático superficial.

Para Murray et al. (2002), áreas maiores geralmente contêm mais espécies do que áreas menores. No entanto, Oertli et al. (2001), ao contrário do que seria esperado para a teoria biogeográfica, em que áreas maiores apresentam maiores valores de riqueza, verificaram que há tendência de estabilizar o número de espécie em áreas grandes. Para esses autores, grandes áreas não podem ser ignoradas, uma vez que elas podem abrigar espécies extintas de áreas menores e algumas espécies ocorrem em áreas grandes e outras em pequenas.

Os murundus com maiores áreas e volumes apresentaram maior abundância e área basal da vegetação arbórea e arbustiva. Oliveira-Filho (1992, 1988) encontrou resultados similares, porém indicando que essa relação não é tão acentuada entre os murundus maiores. Nesse sentido, a área e volume do murundu podem limitar a ocorrência de espécies e influenciar a estrutura da comunidade vegetal lenhosa.

Além das variáveis destacadas nesta pesquisa, a profundidade do lençol freático e parâmetros físicos e químicos do solo podem ser indicados para estudos com foco na composição e estrutura da comunidade.

\section{CONCLUSÃO}

Área e volume influenciaram a abundância e riqueza, corroborando o pressuposto da teoria da biogeografia de ilhas. A área e volume influenciaram a área basal e podem estar relacionados ao tempo de formação do murundu e ao tempo de colonização.

\section{REFERÊNCIAS}

ABDON, M. M.; SILVA, J. S. V. Identificação de padrões em imagens landsat-ETM+ para interpretação da vegetação arbórea do Cerrado na sub-região de Cáceres, no Pantanal do estado de Mato Grosso. In: SEMANA DE GEOGRAFIA. DA UNEMAT, 9., 2008, Cáceres. Anais... Cáceres: Unemat, 2008. CD ROM.

ALMEIDA JR, E. B. et al. Caracterização da vegetação de restinga da RPPN de Maracaípe, PE, Brasil, com base na fisionomia, flora, nutrientes do solo lençol freático. Acta Botânica Brasileira, v.23, n.1, p.36-48, 2009.

ARAÚJO NETO, M. D. et al. The “mounds” of the “cerrado” region of Central Brazil. Journal Tropical of Ecology, v.2, p.17-35, 1986.

ARIEIRA, J.; CUNHA, C. N. Fitossociologia de uma floresta inundável monodominante de Vochysia divergens Pohl (Vochysiaceae), no Pantanal Norte, MT, Brasil. Acta Botanica Brasilica, v.20, n.3, p.569-580, 2006.

BORDIGNON, L. et al. Ilhas Vegetacionais no Pantanal Matogrossense: um teste da teoria de Biogeografia de Ilhas. Revista Brasileira de Ciências, v.5, n.1, p.387-389, 2007.

BRASIL. Ministério das Minas e Energia. Secretaria-Geral. Projeto RADAMBRASIL. Folha SE-21 Corumbá; Geologia, Geomorfologia, Pedologia, Vegetação e uso Potencial da Terra. Levantamento de Recursos Naturais. 25ed. Rio de Janeiro: 1982. 640p.

CUNHA, C. N.; JUNK, W. J. Composição florística de capões e cordilheiras: localização de espécies lenhosas quanto ao gradiente de inundação no Pantanal de Poconé-MT. In: SIMPÓSIO DE RECURSOS NATURAIS E SOCIO-ECONÔMICOS DO PANTANAL, 1999, Corumbá. Anais... Corumbá: 1999. v.2. p.134-148.

Revista Árvore, Viçosa-MG, v.38, n.3, p.443-451, 2014 
FIDALGO, O.; BONONI, V. L. R. Manual prático de coleta, herborização e preservação. São Paulo: Instituto de Botânica do Estado de São Paulo, 1984.

FURLEY, P. A. Classification and distribution of mounds in the Cerrado of central Brazil. Journal of Biogeography, v.13, p.265-268, 1986.

JUNK, W. J.; CUNHA, C. N. Pantanal: a large South American. wetland at a crossroads. Ecological Engineering, v.24, n.4, p.91-40, 2005.

MACARTHUR, R. H.; WILSON, E. O. The theory of Island Biogeography. Princeton: University Press, 1967. 203p.

MACEDO, M.; FERREIRA, A. R.; DA SILVA, C. J. Estudos da dispersão de cinco espécies-chave em um capão no Pantanal de Poconé, Mato Grosso In: SIMPÓSIO SOBRE RECURSOS NATURAL E SOCIOECONÔMICO DO PANTANAL DESAFIOS E SUSTENTABILIDADE, 3., 2000, Corumbá. Anais... Corumbá: 2000.

MARIMON, B. S. et al. Estrutura da vegetação e características dos campos de murundus do Parque Estadual do Araguaia, Mato Grosso. In: CONGRESSO DE ECOLOGIA DOBRASIL. 2009. LOCAL.

Resumos... São Lourenço-MG: 2009. p.1-2.

MARIMON, B. S.; LIMA, E. S. Caracterização Fitofisionômica e Levantamento Florístico Preliminar no Pantanal dos Rios MortesAraguaia, Cocalinho, Mato Grosso, Brasil. Acta Botanica Brasilica, v.15, n.2, p.213-229, 2001.

MUELLER-DOMBOIS, D.; ELLENBERG, H. Aims and methods in vegetation ecology. New York: John Wiley \& Sons, 1974.

MURRAY, K. G.; WINNETT-MURRAY, K.;

HERTEL, L. Species diversity, island biogeography, and the design of nature reserves. In: ASSOCIATION FOR BIOLOGY LABORATORY EDUCATION -ABLE. 2002. Disponível em: <http:/ /www.ableweb.org/volumes/vol-23/8-murray.pdf>

OERTLI, B. et al. Does size matter? The relationship between pond area and biodiversity. Biological Conservation, v.104, p.59-70, 2002.

Revista Árvore, Viçosa-MG, v.38, n.3, p.443-451, 2014
OLIVEIRA-FILHO, A. T. A vegetação de um campo de manchões microrrelevo associados a cupins na região de Cuiabá - MT. 1988. 182f. Tese (Doutorado em Ciências Ecologia) - Instituto de Biologia, Universidade de Campinas, São Paulo, 1988.

OLIVEIRA-FILHO, A. T. Floodplain” Murundus” of Central Brasil: evidence for the termite- origin hypothesis. Journal of Tropical Ecology, v.8, n.1, p.1-19, 1992.

PONCE, V. M.; CUNHA, C. N. Vegetated earthmounds in tropical savannas of central Brazil: a synthesis. With special reference to the Pantanal do Mato Grosso. Journal of Biogeography, v.20, p.219-225, 1993.

RESENDE, I. L. M. et al. A comunidade vegetal e as características abióticas de um campo de murundu em Uberlândia, MG. Acta Botânica Brasileira, v.18, n.1, p.9-17, 2004.

REBELLATO, L.; CUNHA, C. N. Efeito do "fluxo sazonal mínimo da inundação" sobre a composição e estrutura de um campo inundável no Pantanal de Poconé, MT, Brasil. Acta Botânica Brasileira, v.19, n.4, p.789-799, 2005.

SANTOS, S. J. et al. Mapeamento de áreas alagadas no Bioma Pantanal a partir de dados multitemporais TERRA / MODIS. In: SIMPÓSIO DE GEOTECNOLOGIA NO PANTANAL, 2., 2009, Corumbá. Anais... Mato Grosso do Sul: INPE, 2009. p.961-970.

SHEPHERD, G. J. FITOPAC 2. Manual do usuário. Campinas: Departamento de Botânica, Universidade Estadual de Campinas, 2010.

SOUZA, V. C.; LORENZI, H. Botânica sistemática: guia ilustrado para identificação das famílias de fanerógamas nativas e exóticas no Brasil, baseado em APG 2. 2.ed. Nova Odessa: 2012. 704p.

SILVA, M. P. et al. Distribuição e quantificação de classes de vegetação do Pantanal através de levantamento aéreo. Revista Brasileira de Botânica, v.23, n.2, p.143-152, 2000. 
SILVA, L. C. R. et al. Deciphering earth mound origins in central Brazil. Plant Soil, v.336, p.314, 2010.
SOARES, J. J.; OLIVEIRA, A. K. M. O Paratudal do Pantanal de Miranda, Corumbá-MS, Brasil. Revista Árvore, v.33, n.2, p.339-347, 2009. 